14.01

\title{
Получение цилиндрических магнитных наночастиц для функционализации полиэлектролитных микрокапсул
}

\author{
() И.М. Долуденко, ${ }^{1}$ А.В. Михеев, ${ }^{1,2}$ И.А. Бурмистров, ${ }^{1}$ Д.Б. Трушина, ${ }^{1,3}$ T.Н. Бородина, ${ }^{1,3}$ T.В. Букреева, ${ }^{1,4}$ \\ Д.Л. Загорский ${ }^{1}$ \\ ${ }^{1}$ Федеральный научно-исследовательский центр „Кристаллография и фотоника“ РАН, \\ 119333 Москва, Россия \\ ${ }^{2}$ Московский государственный университет им. М.В. Ломоносова, \\ 119991 Москва, Россия \\ ${ }^{3}$ Первый Московский государственный медицинский университет им. И.М. Сеченова, \\ 119991 Москва, Россия \\ ${ }^{4}$ Национальный исследовательский центр „Курчатовский институт“, \\ 123098 Москва, Россия \\ e-mail: doludenko.i@yandex.ru
}

Поступило в Редакцию 16 декабря 2019 г.

В окончательной редакции 16 декабря 2019 г.

Принято к публикации 17 февраля 2020 г.

Решалась задача создания магнитных полимерных капсул, перспективных для адресной доставки лекарств. Для этой цели были использованы цилиндрические магнитные наночастицы. Предложен способ получения таких частиц, состоящий в синтезе слоевых нанопроволок с чередующимися слоями требуемого магнитного металла и „жертвенными“ слоями немагнитного металла. Методом матричного синтеза на основе гальванического осаждения (с переменным потенциалом) требуемых металлов в поры трековых мембран были получены проволоки диаметром $100 \mathrm{~nm}$ со слоями никеля 400 или $200 \mathrm{~nm}$. Отработан способ последующего выделения никелевых фрагментов путем селективного травления (удаления) медных промежутков. Рассмотрены возможности предотвращения агрегации образовавшихся магнитных наночастиц и их внедрения в оболочки полимерных капсул.

Ключевые слова: магнитные наночастицы, матричный синтез, полимерные капсулы, адресная доставка лекарств.

DOI: 10.21883/JTF.2020.09.49673.414-19

\section{Введение}

Известно, что магнитные частицы активно применяются в биологии и медицине. Так, актуальной и активно решаемой задачей в настоящее время является так называемая „адресная доставка лекарств,. Для эффективного лечения лекарство, вводимое в организм, должно попадать в определенную область организма и действовать именно там. (Очевидно, что при воздействии на весь организм необходимы большие дозы лекарств, при этом велика вероятность их побочного действия). Одним из путей решения этой задачи является инкапсуляция введение лекарства в оболочку (капсулу), с помощью которой и происходит адресная доставка. Работа в этом направлении активно ведется в последние 10-15 лет.

Успехи применения полимерных многослойных капсул для доставки лекарственных веществ, а также подходы для их контролируемого высвобождения представлены в [1]. Анализ различных методов создания капсул, внедрения лекарственных молекул внутрь капсул и в их оболочку, возможные способы функционализации оболочек приведены в [2]. В более поздней работе [3] дан обзор применения полиэлектролитных и нанокомпозитных микрокапсул, (полученных методом послоевого осажде- ния) для инкапсуляции и доставки лекарств, с целью диагностики. Рассмотрены различные способу улучшения функциональных свойств капсул, воздействия внешних факторов, таких как ультразвук, внешние магнитные поля (МП), лазерное или коротковолновое облучение. Так, отмечено, что для вскрытия капсул может использоваться кратковременное воздействие ультразвуки и/или инфракрасного облучения.

Одним из путей функционализации капсул является внедрение в капсулы магнитных частиц, при этом доставка капсулы в требуемое место может осуществляться МП. (Отметим, что такой подход не решает многих проблем, например, известно, что распространение капсул будет определяться в первую очередь сильным кровотоком, и корректировать движение дополнительно полем бывает достаточно сложно. Метод эффективно работает в сосудах с малым кровотоком.) Этому направлению посвящена серия работ. Так, в [4] полиэлектролитные капсулы с целью их магнитной доставки модифицировали путем электростатической адсорбции предварительно синтезированных наночастиц магнетита на заряженную поверхность оболочки. Другой подход предложен в работах [5-7] - магнитные наночастицы 
были синтезированы непосредственно на оболочке капсулы.

С помощью магнитных частиц, внедренных в полимерную капсулу, может решаться и другая задача это локальный нагрев. Задача повысить температуру в определенной части организма возникает, например, в связи с необходимостью точечного теплового воздействия на больной орган (или клетки определенного типа - например, раковые).

Эта задача решается путем воздействия переменного МП на капсулы с магнитными частицами, заранее „доставленными,в требуемое место. МП определенной частоты приводит к нагреву таких частиц - энергия поля преобразуется в тепловую. Часто при этом удается не только осуществить вышеописанный нагрев (гипертермию), но и обеспечить контролируемое высвобождение инкапсулированного лекарства [8,9]. В работе [10]. Отмечено, что эффективность преобразования энергии МП в тепловую энергию можно повысить, используя для включения в оболочку капсул наночастицы с формой, отличной от сферической, например, кубической.

Еще одна задача, решаемая путем внедрения магнитных частиц в капсулу с лекарством - это активизация действия капсулы с лекарством. Например, в работе [11] импульсное МП (0.18T) использовали для воздействия на магнитные коллоидосомы, что приводило к их итерационному сжатию и высвобождению инкапсулированного вещества. Этот подход обеспечивает устойчивое высвобождение, контролируемое циклами сжатия и релаксации коллоидосом, однако используемые капсулы (диаметр до $500 \mu \mathrm{m}$ ) слишком велики для доставки лекарств in vivo. Переменное МП представляет собой универсальное внешнее воздействие для вскрытия магнитных микрокапсул при их биомедицинских применениях. Ткани организма человека прозрачны для такого воздействия и не повреждаются им. Действие переменного низкочастотного МП на капсулу (уже находящуюся в требуемом месте) приводит к вращательному или колебательному движению магнитных частиц в оболочке капсулы, при этом энергия магнитного поля переходит в механическую энергию. Движение частиц вызывает локальное или полное разрушение оболочки капсулы, приводящее к высвобождению лекарства. До сих пор эту задачу пытались решить применяя магнитные наночастицы (например, магнетита: [12]), которые имеют форму, близкую к сферической, что, очевидно, не является оптимальным вариантом. Создание магнитных частиц для биомедицинских применений требует решения и других задач. Так, часто на поверхности магнитной частицы необходимо создать защитный слой. В работе [13] в порах пористого оксида алюминия (диаметр $50 \mathrm{~nm}$ ) были получены методом электроосаждения нанопроволок (НП) из железа длиной либо $15 \mu \mathrm{m}$ (поликристаллические), либо $1 \mu \mathrm{m}$ (монокристаллические). Путем дальнейшего окисления (в матрице при температуре $150^{\circ} \mathrm{C}$, время процесса от $10 \mathrm{~min}$ до $72 \mathrm{~h}$ ) на поверхности создавался слой оксида $\mathrm{Fe}_{3} \mathrm{O}_{4}$.
Созданный слой оксида предотвращал НП от дальнейшего окисления при комнатной температуре. Созданные таким образом структуры типа „ядро-оболочка, были изучены методами магнитометрии и магнито-силовой микроскопии. Показано, что их магнитные свойства сильно зависят от условий приготовления и от толщины оболочки (намагниченность насыщения и остаточная намагниченность уменьшаются с утолщением оболочки). Так же показано, что такие НП, покрытые оксидной оболочкой, имеют высокую биосовместимость.

Общий обзор задач и возможностей применения магнитных частиц для терапии и диагностики дан в работе [14]. Там также говорится о том, что одним из способов усиления энергетического действия МП на биохимическую систему является введение в нее магнитных наночастиц МНЧ-медиаторов действия поля. Во время пребывания в организме МНЧ становятся основными первичными мишенями для влияния магнитного поля, обеспечивая высокую чувствительность системы к внешним магнитным воздействиям. МНЧ, во-первых, увеличивают (часто на несколько порядков) действие магнитного поля и, во-вторых, локализуют это действие в нужной области (предполагается, что МНЧ доставлены в нужное место). Все это позволяет значительно уменьшить общую интенсивность воздействия и локализовать эффект в нужном месте. Для такого использования МНЧ функционализируют, покрывая одной или несколькими оболочками, содержащими требуемое биоактивное вещество (оболочки с лигандами), радиус такой функционализированной частицы обычно до $100 \mathrm{~nm}$. Кроме того, эти оболочки предохраняют МНЧ от окисления, придают им требуемые гидрофобные свойства, предотвращают агрегирование и понижают цитотоксичность. Помимо таких МНЧ с лигандными оболочками, используют так называемые капсулы, там биоактивное вещество содержится в центре, который окружен оболочками с магнитными частицами (радиус таких нанокапсул до $100-300 \mathrm{~nm}$ ). При воздействии внешнего поля на такие системы происходит так называемая магнитомеханическая активация МНЧ - в зависимости от поля (постоянное - переменное, однородное - неоднородное) они могут вращаться, перемещаться, совершать вращательно-колебательное или поступательно-колебательное движение. Такое движение может приводить к локальному выделению тепла или к разрыву капсулы. Очевидно, что эффект этот зависит от параметров прикладываемого магнитного поля.

Отметим, что во всех описанных случаях частицы имеют неконтролируемую форму, как правило, близкую к сферической. В настоящей работе предложено проводить функционализацию полимерных капсул с помощью магнитных наноразмерных частиц вытянутой формы цилиндрических магнитных наночастиц (ЦМНЧ). Применение таких частиц с заданным аспектным отношением и регулируемым магнитным моментом позволило бы (помимо адресной доставки лекарств) решить задачу управляемого вскрытия полимерных капсул за счет их 
механического разрушения (разрыва). Такое разрушение можно осуществить путем вращения магнитных частиц (находящихся в оболочке капсулы) в переменном магнитном поле определенной частоты. В настоящей работе предложено использовать в качестве магнитных частиц наноразмерные фрагменты НП. Идея подхода состоит в получении гетероструктурных НП, состоящих из слоев магнитного металла (Ni) заданной длины, чередующихся со слоями другого металла $(\mathrm{Cu})$, который впоследствии будет удален (так называемыми ,жертвенными слоями“). Такие НП получаются методом матричного синтеза на основе электрохимического заполнения трековых мембран. Основные идеи матричного синтеза изложены в работе [15]. Получение одной из разновидностей таких наноструктур - „слоевых“ НП - известно давно и описано в ряде работ. Современное состояние вопроса, в том числе особенности получения слоевых НП, рассмотрено, в частности, в монографии [16]. В одной из работ предложен способ разделения таких слоевых НП на фрагменты [17], однако это разделение проводилось для НП, уже закрепленных на поверхности для других целей. Некоторые частные вопросы получения длинных НП из слоев никеля и меди, а также регулирования толщины этих слоев, описаны авторами настоящей работы в [18]. Процесс проводился в электролите, содержащем ионы обоих металлов. Чередование слоев различного состава достигалось за счет периодического изменения ростового напряжения. После удаления ростовой полимерной матрицы образцы были изучены методами сканирующей $(\mathrm{CЭМ)} \mathrm{и} \mathrm{просвечивающей} \mathrm{(ПЭМ)} \mathrm{электронной}$ микроскопии, которые показали образование чередующихся слоев различного состава. Задачей настоящей работы была отработка методик разделения таких НП на части путем селективного травления. Конечной целью было получение калиброванных по размерам вытянутых частиц ЦМНЧ и изучение возможности их включения в оболочки многослойных полиэлектролитных микрокапсул.

\section{1. Экспериментальная часть}

\section{1. Материалы и методы}

В настоящей работе в качестве ростовой матрицы применялись полупромышленные трековые мембраны производства ОИЯИ, г. Дубна: мембраны на основе ПЭТФ (полиэтилентерефталата) толщиной $12 \mu \mathrm{m}$, диаметр пор $100 \mathrm{~nm}$; плотность пор $-1.2 \cdot 10^{9} \mathrm{~cm}^{-2}$. Для проведения процесса электроосаждения с одной стороны матрицы наносился (термическое вакуумное напыление на ВУП-4) тонкий проводящий слой меди. В дальнейшем напыленный слой гальванически укреплялся $\left(\mathrm{CuSO}_{4} \cdot 5 \mathrm{H}_{2} \mathrm{O}-200 \mathrm{~g} / \mathrm{l} ; \mathrm{H}_{2} \mathrm{SO}_{4}-10 \mathrm{~g} / \mathrm{l}\right)$ для создания сплошного проводящего слоя, который и являлся в дальнейшем рабочим электродом. Для проведения процессов электроосаждения применялся электролит следующего состава: $\mathrm{NiSO}_{4} \cdot 7 \mathrm{H}_{2} \mathrm{O}-0.7 \mathrm{M} ; \mathrm{CuSO}_{4} \cdot 5 \mathrm{H}_{2} \mathrm{O}-$
$0.025 \mathrm{M} ; \mathrm{H}_{3} \mathrm{BO}_{3}-0.51 \mathrm{M}$, где $\mathrm{M}$ - молярность в $\mathrm{mol} / \mathrm{l}$. Применялась специально сконструированная в СКБ ФНИЦ „Кристаллография и фотоника, РАН гальваническая ячейка с площадью осаждаемого образца $2.5 \mathrm{~cm}^{2}$. В качестве источника тока для проведения электроосаждения применялся потенциостат-гальваностат Р-2X компании Elins. Прибор позволял проводить временную запись гальванического процесса.

Для создания полимерных микрокапсул (ПЭК) использовались следующие материалы и реактивы: хлорид кальция $\mathrm{CaCl}_{2}$, карбонат натрия $\mathrm{Na} 2 \mathrm{CO} 3$ („Acros Organics,», США), Поли (аллиламин гидрохлорид) (ПАХ) и полистиролсульфонат (ПСС), хлорид натрия $\mathrm{NaCl}$, тринатриевая соль этилендиаминтетрауксусной кислоты (ЭДТА), полисорбат 80, таниновая кислота („Sigma-Aldrich“, Германия). Во всех экспериментах использовали деионизованную воду, полученную на установке водоочистки Millipore Milli-Q Plus (США, Канада).

Размеры и морфологию получаемых ЦМНЧ и ПЭК изучали с помощью СЭМ на приборах JCM-6000plus Ltd. с приставкой для элементного анализа, JSM-7401F (JEOL, Япония). Приборы работали в режиме вторичных электронов.

Измерение дзета-потенциала поверхности ПЭК в суспензии проводили с помощью автоматического анализатора Zetasizer Nano ZS (Malvern, Великобритания) при $25^{\circ} \mathrm{C}$.

\section{2. Эксперимент и результаты}

Электроосаждение нанопроволок проводилось послойно в поры трековых мембран. Режим электроосаждения подразумевал осаждение отдельных слоев никеля (магнитных слоев, выделяемых затем в виде единичных ЦМНЧ) и медных слоев (жертвенных). Такой режим позволял в одном поровом канале синтезировать большое количество ЦМНЧ. При этом последовательное осаждение различных металлов достигалось путем последовательного изменения потенциала во время

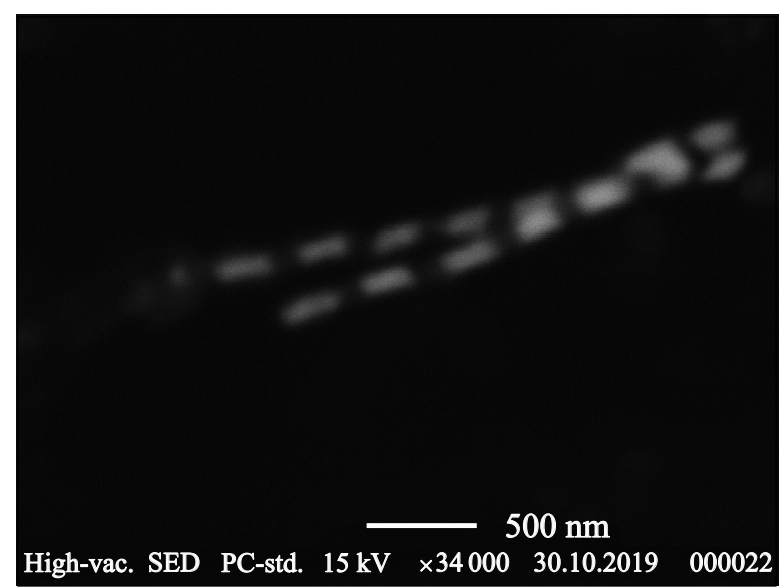

Рис. 1. СЭМ-изображение взвеси слоевых НП. 
роста. Для слоя меди он составлял $0.7 \mathrm{~V}$, для слоя никеля - $1.8 \mathrm{~V}$ [18].

Отработка режима получения гетероструктурных НП контролировалась методом СЭМ. При этом перед исследованием массив НП отделялся от ростовой полимерной матрицы, затем НП отделялись от медной подложки („сбивались“ с подложки в ультразвуковой ванне). Отметим, что предварительная отработка режима проводилась на НП, состоящих из слоев меди и кобальта, поскольку комбинация этих металлов позволяла получить достаточно четкий контраст при микроскопических исследованиях. Пример СЭМ-изображения получаемой взвеси слоевых НП представлен на рис. 1.

На СЭМ-изображениях НП четко выделяются отдельные слои. Так же были проанализированы различные режимы роста. Показано, что для более точного контроля толщины осаждаемых слоев, лучшим является режим при котором потенциал изменялся в зависимости от протекшего заряда (начало данного исследования описано в [19]). Использовались два режима: толщина медных слоев во всех случаях составляла $100 \mathrm{~nm}$, а толщина никелевых - $200 \mathrm{~nm}$ в первом и $400 \mathrm{~nm}$ во втором. Количество периодов осаждения было 10 и 5 соответственно. После электроосаждения матрица удалялась в концентрированной щелочи $\mathrm{NaOH}$ при температуре $60^{\circ} \mathrm{C}$ в течении $2 \mathrm{~h}$. Целью следующего этапа было разделение полученной слоевой НП на отдельные фрагменты. Это достигалось путем удаления „жертвенных“ слоев и медной подложки методом селективного травления. В настоящей работе были опробованы 4 варианта травителей. Первый - раствор $\mathrm{NH}_{4} \mathrm{OH}$ $(150 \mathrm{~g} / 1)$ в воде с добавлением $1 \mathrm{~g} / 1 \mathrm{CuSO}_{4} \cdot 7 \mathrm{H}_{2} \mathrm{O}$. Данный состав растворял медь и не вступал в реакцию с никелем. Основным его недостатком было долгое время травления (порядка $72 \mathrm{~h}$ при комнатной температуре). Для ускорения процесса применялся раствор лимонной кислоты $(300 \mathrm{~g} / 1)$ и $\mathrm{NaCl}(50 \mathrm{~g} / \mathrm{l})$ в $\mathrm{H}_{2} \mathrm{O}_{2}$. Недостатком данного раствора являлась бурная реакция с медью и более медленная с никелем. Отследить момент полного растворения меди без критических повреждений никелевого слоя было невозможно. Для снижения скорости травления и агрессивности травителя он разбавлялся водой в 2 и в 4 раза. В случае разбавления раствора в 2 раза процесс замедлялся, но все равно реагировал с функциональной частью (никелевый слой). Травитель, разбавленный в 4 раза, показал наилучшие результаты. Он не реагировал с функциональной частью НП и в то же время процесс растворения меди занимал порядка 1h. Таким образом, можно сделать вывод о том, что оптимальным вариантом селективного травителя меди в присутствии никеля является раствор следующего состава: $\mathrm{H}_{2} \mathrm{O}_{2}-250 \mathrm{~g} / \mathrm{l}$; (HOOCCH2) $2 \mathrm{C}(\mathrm{OH}) \mathrm{COOH}-$ $75 \mathrm{~g} / \mathrm{l} ; \mathrm{NaCl}-12.5 \mathrm{~g} / \mathrm{l}$.

Электронная микроскопия взвеси ЦМНЧ После получения взвеси ЦМНЧ исследовались методами СЭМ. Пример полученных изображений выделенных частиц приведен на рис. 2.

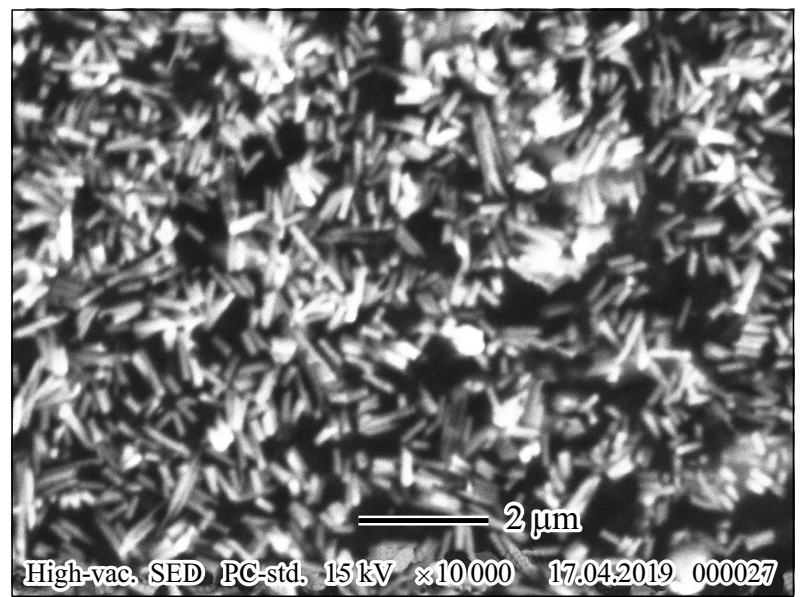

Рис. 2. СЭМ-изображение агломератов никелевых ЦМНЧ.

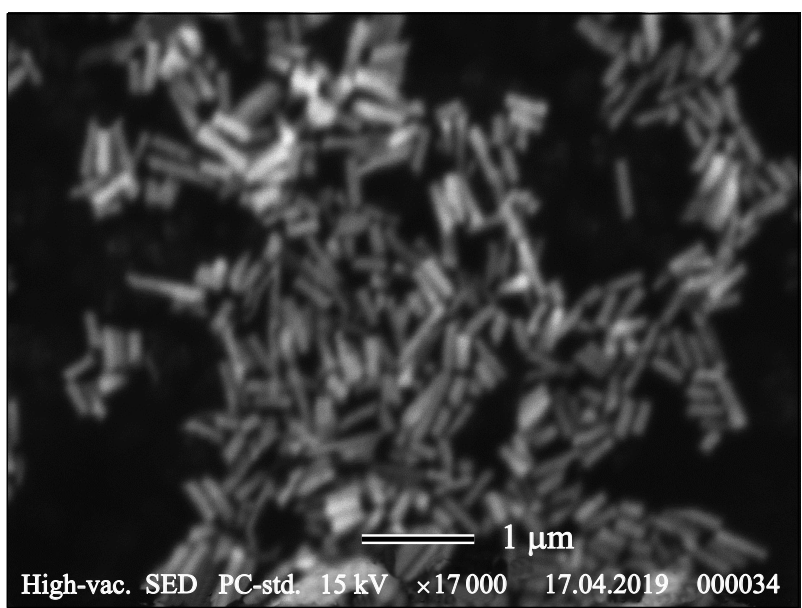

Рис. 3. СЭМ-изображение ЦМНЧ после модификации.

Анализ изображений показывает, что частицы имеют одинаковый размер, который соответствует задаваемому режиму электроосаждения. Также было выявлено, что частицы в большинстве случаев агрегируют - этот нежелательный процесс необходимо было минимизировать.

Модификация поверхности ЦМНЧ. Для снижения агрегации магнитных ЦМНЧ их поверхность модифицировали заряженными молекулами. Для этого к водной суспензии частиц добавляли раствор полисорбата 80 или таниновой кислоты концентрацией $2 \mathrm{mg} / \mathrm{ml}$, инкубировали на шейкере $15 \mathrm{~min}$, затем модифицированные частицы отделяли от водной фазы и хранили в виде водной суспензии. Пример модифицированного массива ЦМНЧ представлен на рис. 3. Данный метод позволял уменьшить агрегацию частиц.

Целью следующего этапа было внедрение ЦМНЧ в оболочку полиэлектролитных капсул (ПЭК).

Получение микрокапсул с ЦМНЧ. Коллоидные частицы карбоната кальция получали как продукт мас- 


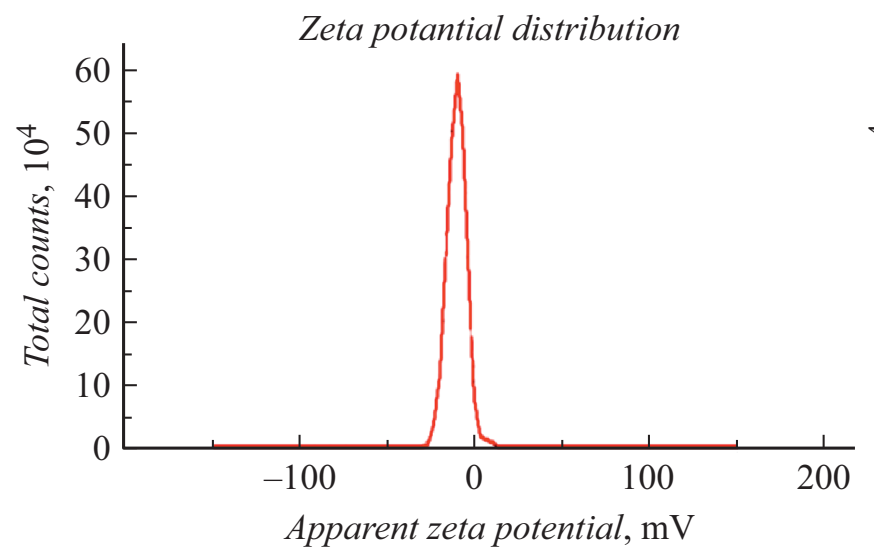

$b$

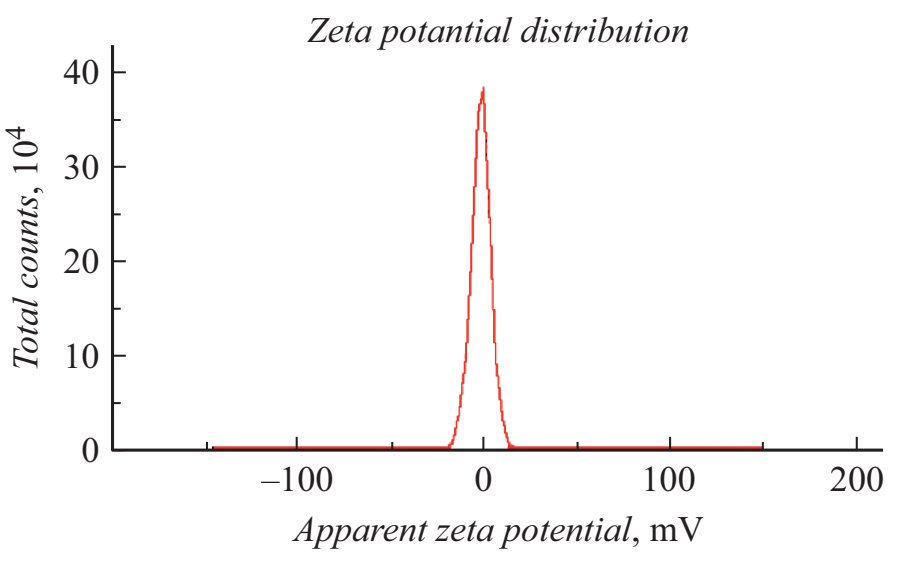

Рис. 4. Значения дзета-потенциала ЦМНЧ: $a-200, b-400 \mathrm{~nm}$.
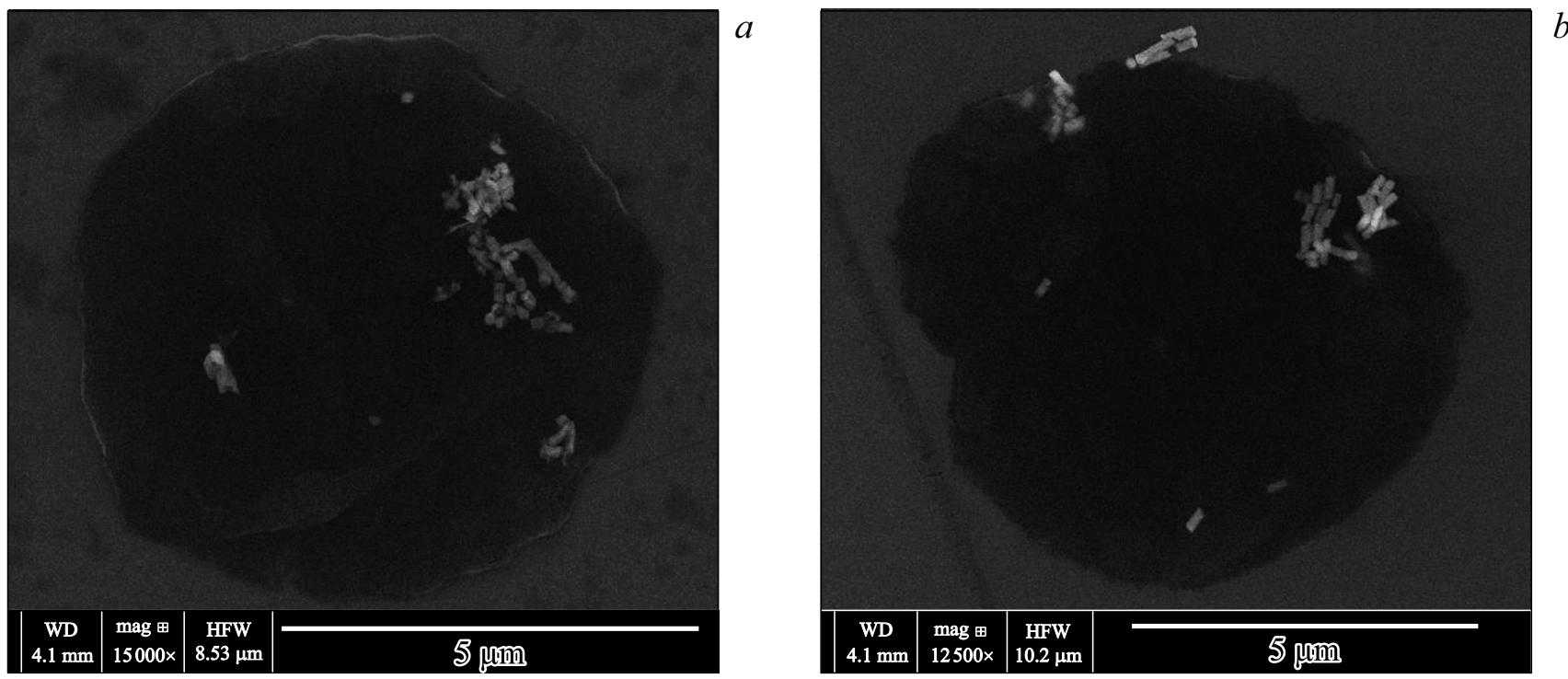

Рис. 5. СЭМ-изображения полимерных микрокапсул (ПАХ/ПСС) 3 с ЦМНЧ длиной $200(a)$ и 400 nm $(b)$ в оболочке полимерной капсулы.

совой кристаллизации в соответствии с реакцией $\mathrm{CaCl}_{2}+\mathrm{Na}_{2} \mathrm{CO}_{3}=\mathrm{CaCO}_{3}+2 \mathrm{NaCl}$. Для получения частиц микронных размеров использовали известную методику: эквивалентные объемы растворов $\mathrm{CaCl}_{2}$ и $\mathrm{Na}_{2} \mathrm{CO}_{3}$ концентрацией $0.1 \mathrm{M}$ смешивали в сосуде с магнитной мешалкой со скоростью $500 \mathrm{rpm}$ в течение $30 \mathrm{~s}$ при температуре $25^{\circ} \mathrm{C}$. После перемешивания суспензию образовавшихся сферических микрочастиц оставляли на 5-7 min для завершения кристаллизации карбоната кальция. Затем частицы $\mathrm{CaCO}_{3}$ трижды промывали от ионов $\mathrm{Na}^{+}$и $\mathrm{Cl}^{-}$деионизованной водой. Для формирования полиэлектролитной оболочки на частицах $\mathrm{CaCO}_{3}$ использовали метод послойной адсорбции противоположно заряженных макромолекул. Оболочка состояла из пары полиэлектролитов - поли (аллиламин гидрохлорида) (ПАХ) и полистирол сульфонат (ПСС).
Микрочастицы карбоната кальция имеют слабо отрицательный поверхностный заряд, поэтому в качестве первого слоя наносили положительный полиэлектролит ПАХ. К $0.015 \mathrm{~g}$ частиц $\mathrm{CaCO}_{3}$ добавляли $1 \mathrm{ml}$ раствора ПАХ в $0.15 \mathrm{M} \mathrm{NaCl}$. Суспензию перемешивали в течение 15 min с помощью минишейкера, затем центрифугировали $3 \mathrm{~min}$, после чего отбирали супернатант, а частицы трехкратно промывали водой. Затем проводили такую же процедуру, используя $1 \mathrm{ml}$ раствора полианиона (в качестве полианиона применялся ПСС) в $0.15 \mathrm{M} \mathrm{NaCl}$. Для предотвращения агрегации частиц при нанесении первых двух слоев пробирки с суспензией помещали на $10 \mathrm{~s}$ в ультразвуковую ванну (Elma Elmasonic S10H, Германия, частота $35 \mathrm{kHz}$ ). НП, использующиеся в работе, имели небольшой отрицательный заряд, поэтому их включение в оболочку проводили с помощью адсорбции на слой 
Изменение дзета-потенциала при формировании полиэлектролитных капсул

\begin{tabular}{|c|c|c|}
\hline Последовательность нанесения слоев & \multicolumn{2}{|c|}{ Дзета-потенциал, mV } \\
\hline $\mathrm{CaCO}_{3}$ & \multicolumn{2}{|c|}{$0 \pm 1$} \\
\hline $\mathrm{CaCO}_{3} / \Pi \mathrm{AX}$ & \multicolumn{2}{|c|}{$3 \pm 1$} \\
\hline $\mathrm{CaCO}_{3} / \Pi \mathrm{AX} / \Pi C \mathrm{C}$ & \multicolumn{2}{|c|}{$-22 \pm 2$} \\
\hline 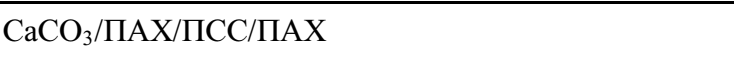 & \multicolumn{2}{|c|}{$7 \pm 2$} \\
\hline \multirow{2}{*}{ 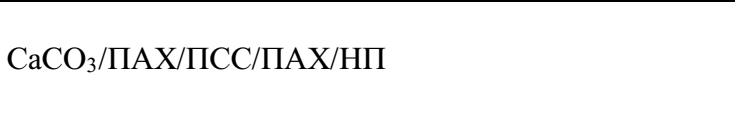 } & НП $200 \mathrm{~nm}$ & НП $400 \mathrm{~nm}$ \\
\hline & $-24 \pm 2$ & $-12 \pm 1$ \\
\hline 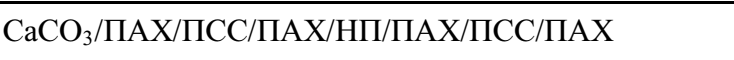 & $6 \pm 2$ & $5 \pm 1$ \\
\hline $\begin{array}{l}\text { Капсулы ПАХ/ПСС/ПАХ/НП/ПАХ/ПСС/ПАХ после } \\
\text { растворения } \mathrm{CaCO}_{3}\end{array}$ & $8 \pm 2$ & $7 \pm 1$ \\
\hline
\end{tabular}

положительно заряженного полиэлектролита. В настоящей работе были получены капсулы со следующим составом оболочек: ПАХ/ПСС/ПАХ/НП/ПСС/ПАХ/ПСС. После нанесения необходимого числа слоев в суспензию добавляли $0.2 \mathrm{M}$ раствор ЭДТА с $p H 7.5$ для растворения частиц $\mathrm{CaCO}_{3}$. После $15 \mathrm{~min}$ инкубирования с ЭДТА капсулы трижды промывали водой. Полученные капсулы хранили при температуре $4^{\circ} \mathrm{C}$ в виде водной суспензии.

Полученные ЦМНЧ включены в оболочку полимерных капсул методом электростатической адсорбции. Для оптимизации включения частиц в оболочки был измерен их дзета-потенциал, значение которого составило $-8 \pm 2$ и $-4 \pm 1 \mathrm{mV}$ для ЦМНЧ длиной 200 и $400 \mathrm{~nm}$ соответственно (рис. 4). В связи с отрицательным поверхностным зарядом ЦМНЧ адсорбировали на слой положительно заряженного полиэлектролита.

В таблице представлены значения дзета-потенциалов для частиц $\mathrm{CaCO}_{3}$ с полиэлектролитными слоями. Переключение знака заряда при чередовании полианиона и поликатиона характеризует послойный характер формирования капсул. При нанесении слоя ЦМНЧ дзетапотенциал меняет свой знак, что свидетельствует об успешной адсорбции частиц на слой ПАХ. Образцы капсул с 200 и $400 \mathrm{~nm}$ ЦМНЧ имеют совпадающие в пределах погрешности дзета-потенциалы, что говорит об отсутствии влияния размеров использованных НП на стабильность капсул.

Исследование капсул с помощью СЭМ подтвердили наличие ЦМНЧ в составе оболочки капсул (рис. 5).

На СЭМ-изображении видно, что ЦМНЧ включаются в полимерную оболочку, что и являлось целью настоящей работы. Отметим, что распределены частицы неравномерно, что предположительно связано с их агрегацией. С целью дальнейшего снижения агрегации ЦМНЧ и улучшения свойств их поверхности они были покрыты поверхностно-активными веществами. Анализ электронно-микроскопических изображений образцов капсул, сформированных с применением модифицированных ЦМНЧ, показал, что модификация их поверхности несколько уменьшает агрегацию частиц и при этом не влияет на эффективность включения НП в полиэлектролитную оболочку.

Дальнейшая оптимизация включения ЦМНЧ в оболочки будет заключаться в поиске более эффективных методов предотвращения сильной агрегации частиц, в том числе за счет их пассивации и временного перевода в немагнитное состояние (например, за счет нагрева).

\section{Выводы}

В работе предложен способ создания магнитных наночастиц цилиндрической формы из слоевых нанопроволок, полученных методом матричного синтеза в порах трековых мембран. На примере НП из чередующихся слоев меди и никеля показана возможность отделения магнитных частиц (никелевых цилиндров) путем селективного вытравливания “жертвенных" слоев второго металла (меди). Предложены способы обработки таких частиц - пассивация, которая уменышает их агрегацию. Продемонстрирована возможность включения НП длиной 200 и $400 \mathrm{~nm}$ в микрокапуслы (ПАХ/ПСС) 3.

\section{Благодарности}

Работа выполнена при поддержке Министерства науки и высшего образования в рамках выполнения работ по Государственному задания ФНИЦ „Кристаллография и фотоника“ РАН с использованием оборудования ЦКП ФНИЦ „Кристаллография и фотоника“ РАН при поддержке Министерства образования и науки России (проект RFMEFI62119X0035) в части синтеза магнитных нанопроволок и их характеризации. Авторы выражают благодарность Апелю П.Ю. (ОИЯИ, г. Дубна) за предоставление трековых мембран и Камышинскому Р. за изучение образцов капсул методом сканирующей микроскопии. Магнетизированные капсулы получены при частичной поддержке гранта РФФИ № 18-53-34007 „Куба_т“. 


\section{Конфликт интересов}

Авторы заявляют, что у них нет конфликта интересов.

\section{Список литературы}

[1] De Cock L.J., De Koker S., De Geest B.G., Grooten J., Vervaet C., Remon J.P., Sukhorukov G.B., Antipina M.N. // Angew. Chem. Int. Ed. 2010. Vol. 49. P. 6954-6973.

[2] Tong W., Song X., Gao C. // Chem. Soc. Rev. 2012. Vol. 41. P. $6103-6124$.

[3] Timin A.S., Gao H., Voronin D.V., Gorin D.A., Sukhorukov G.B. // Adv. Mater. Interfaces. 2016. 1600338. P. 1-22.

[4] Inozemtseva O.A., Gorin D.A., Portnov S.A., Luklinska Z., Yashchenok A.M., Pavlov A.M., Skirtach A.G., Mohwald H., Sukhorukov G.B. // Phys. Chem. Chem. Phys. 2008. Vol. 10. P. 6899-6905.

[5] Shchukin D.G., Sukhorukov G.B., Möhwald H. // Angew. Chemie Int. Ed. 2003. Vol. 42. N 37. P. 4472-4475.

[6] Nakamura M., Katagiri K., Koumoto K. // J. Colloid Interface Sci. 2010. Vol. 341. N 1. P. 64-68.

[7] Букреева Т.В., Орлова О.А., Сульянов С.Н., Григорьев Ю.В., Дороватовский П.В. // Кристаллография. 2011. Vol. 56. N 5. P. $940-943$.

[8] Hu S., Tsai C., Liao C., Liu D., Chen S. // Langmuir. 2008. Vol. 24. N 20. P. $11811-11818$.

[9] Katagiri K., Imai Y., Koumoto K. // J. Colloid Interface Sci. 2011. Vol. 361. N 1. P. 109-114.

[10] Carregal-Romero S., Guardia P., Yu X., Hartmann R., Pellegrino T., Parak W.J. // Nanoscale. 2015. Vol. 7. N 2. P. 570-576.

[11] Long Y., Liu C., Zhao B., Song K., Yang G., Tung C.H. // NPG Asia Mater. 2015. Vol. 7. N 1. P. e148.

[12] Zheng C., Ding Y., Liu X., Wu Y., Ge L. // Int. J. Pharm. 2014. Vol. 475. N 1-2. P. 17-24.

[13] Ivanov Y.P., Alfadhel A., Alnassar M., Perez J.E., Vazquez M., Chuvilin A., Kosel J. // Sci. Reports. 2016. Vol. 6. P. 24189.

[14] Головин Ю.И., Клячко Н.Л., Мажуга А.Г., Грибановский С.Л., Головин Д.Ю., Жигачев А.О., Шуклинов А.В., Ефремова М.В., Веселов М.М., Власова К.Ю., Усвалиев А.Д., Ле-Дейген И.М., Кабанов А.В. // Российские нанотехнологии. 2018. Т. 13. № 5-6. С. 3-27.

[15] Martin C.R. // Science. 1994. Vol. 266. N 23. P. 1961-1966.

[16] Magnetic Nano- and Microwires: Design / Ed. by Vazquez M. Woodhead, Elsevier. 2015. 962 p.

[17] Yao H., Xie L., Cheng Y., Duan J., Chen Y., Lyu S., Sun Y., Liu J. // Materials \& Design. 2017. Vol. 123. N 5. P. 165-173.

[18] Жигалина О.М., Долуденко И.М., Хмеленин Д.Н., Загорский Д.Л., Бедин С.А., Иванов И.М. // Кристаллография. 2018. T. 63 № 3. С. 455-462.

[19] Загорский Д.Л., Долуденко И.М., Черкасов Д.А., Жигалина О.М., Хмеленин Д.Н., Иванов И.М., Бухараев А.А., Бизяев Д.А., Хайбуллин Р.И., Шаталов С.А. // ФТТ. 2019. Т. 61. Вып. 9. С. $1682-1693$. 